\title{
Correspondence
}

\section{The supervision register}

Sir: Although Phillip Vaughan is rightly concerned that some consultants have not embraced the supervision register (Psychiatric Bulletin, 20, 143-145) he does not mention the possibility that the criteria can be used in different ways by different consultants. The criteria for inclusion may be open to interpretation despite Department of Health assurances (Glover et al, 1994). The guidelines for the register state that, to be included on it, an adverse outcome should be liable to befall a patient "in some forseeable circumstance which it is felt might well arise in this particular case" (NHS Management Executive, 1994). Some consultants may regard the care given to a vulnerable patient as being so good that the circumstances would not arise where the risk of suicide, violence or neglect would increase. Others may consider few such circumstances are foreseeable in any real sense, or that patients with known longstanding, high levels of risk do not come within the criteria because no circumstances would significantly alter the level of risk. Such interpretations of the criteria for the supervision register, which may be more prevalent in those who are less enthusiastic about using it would result in very few patients being included on the register.

GLOVER, G. R., MCCULLCH, A. W. \& JENKINS, R. (1994) Supervision Registers for mentally ill people (letter). Brttish Medical Journal, S09, 809-810.

NHS MANAGEMENT EXECCUTIVE (1994) Introduction of Supervision Registers for Mentally II People from 1 April 1994. HSG (94)5. Leeds: NHSE.

\section{CHRISTOPHER CLARK}

Department of Psychiatry, B Floor South Block, Queen's Medical Centre, Nottingham NG7 2UH

\section{Supervised discharge and the Mental Health Review Tribunals}

Sir: The Mental Health (Patients in the Community) Act 1995 came into force on 1 April 1996. My observation is that an increasing number of legal representatives of detained patients are advising the Mental Health Review Tribunals (MHRTs) that patients be placed on after-care under supervision (Supervised Discharge). In marginal cases where the Tribunal normally would have taken a cautious view and not granted discharge, the representattves are attempting to persuade the Tribunal to effect after-care under supervision.
Since patients on Supervised Discharge have a right to appeal, the Tribunals may soon find themselves in a position whereby one Tribunal recommended Supervised Discharge and another Tribunal heard the application for discharge from it. In that situation, would the Tribunal hearing the application for discharge be considered to be acting independently?

ANIL KUMAR, Calderstones NHS Trust, Whalley, Clitheroe BB7 9PE

\section{CPA ... a post mortem!}

Sir: We reviewed the CPA (care programme approach) documentation of all psychiatric patients from Warrington who died of unnatural causes and were subjects of Coroner's inquests since the implementation of CPA 4 years ago. Of the 31 reported deaths, $19(60 \%)$ were on the CPA register and had had at least one admission since the start of CPA.

Only 9 of the 19 patients (47\%) had an identified care plan. Of the $10(53 \%)$ that had no care plans, seven had alcohol or drugs as a primary diagnosis, two could not be traced and one died while in care. A suicide verdict was returned on seven patients $(37 \%)$, only three of whom had an identified care plan. Twelve (63\%) patients had a verdict of misadventure or an open verdict, six of whom had an identified care plan. None of the deceased had a 'red' (full) CPA reserved for patients with serious mental illness (Jameison, 1996).

CPA documentation of the deceased showed that some needs had been identified but there was no mention of suicide risk, or any other risk in any of the patients. There was also no evidence to suggest that formal reviews had taken place. Based on this limited review of a small number of cases, CPA was not of value in detecting unmet needs or risk in this group of patients.

Jameison, S. (1996) The Care Programmme Approach made simple. Psychiatry in Practice, 13-14.

\section{EMAD SALIB}

TERRY KEEGAN

SHEILA CAWLEY

Winwick Hospital, Warrington Community Health Care (NHS) Trust 